\title{
A STUDY ON ASSOCIATION BETWEEN WORK- RELATED FACTORS AND HYPERTENSION AMONG BUS DRIVERS IN TAMILNADU - A CROSS-SECTIONAL STUDY
}

KEY WORDS:Bus drivers, Hypertension, Work-related Factors, Association
Imtiaz Ahmed S*

\section{PK Govindrajan}

Felix
Post Graduate, Rajah Muthaiah Medical College, Chidambaram. ${ }^{*}$ Corresponding Author

Professor, Rajah Muthaiah Medical College, Chidambaram.

Reader cum Statistician, Rajah Muthaiah Medical College, Chidambaram.

Background and Objective: Hypertension is a Leading cause of Morbidity and Mortality in developing nations. This study aims to Find the Association between Work related risk factors and Hypertension among transport Bus Drivers Method: This study was a Cross Sectional Study carried out in Bus Depot and Bus Stand, Chidambaram, in Cuddalore district of Tamilnadu. The approximate prevalence of HTN among Adults in Tamilnadu was 31.5\% (5). The estimated sample size for the study was 205. The Study tool included were Risk factor questionnaire and Physical measurement of Height,Weight and Blood pressure.

Results: Study showed significant Association between work-related factors or variables with Hypertension. Factors like Duration of Service in Present Job, Bus route travelling, Number of Hours at work, Family history of Hypertension are significantly associated with rise in Blood Pressure

Conclusion: Strong Association between work related factors like Service duration, travelling bus route, Duration of work hours, Shift duties and Hypertension was noted. Study recommends need for Periodic screening and follow up for Early diagnosis and treatment compliance. Lifestyle modifications and Periodic shift in duty patterns is also needed for the benefit of Bus drivers

\section{INTRODUCTION}

Cardiovascular diseases (CVDs) account for nearly a third of all deaths worldwide. The Prevalence of CVDs is increasing in developing countries like India. CVD is predicted to become the major cause of morbidity and mortality by 2020 (1). The key intervention in CVDs is to identify risk factors early and initiate therapy to control them. An important modifiable risk factor for CVDs is systemic arterial hypertension (HTN). Hypertension constitutes an important public health issue. Latest data predict that the number of hypertensive adults will reach 1.5 billion - approximately $30 \%$ of the world population - by 2025(6). Hence, diagnosis of hypertension and appropriate treatment to optimize BP are important public health goals worldwide (2). The aetiology of hypertension involves both genetic and behavioural factors including age, race, positive family history, obesity, diet, sedentary lifestyle, and tobacco and alcohol consumption $(7,8)$. Hypertension has been associated with enlarged threat of coronary artery disease, and cardiovascular and cerebrovascular diseases are also caused by hypertension. A meta-analysis also reported that prehypertension, even in the low range is associated with higher risk of cardiovascular disease and also with chronic kidney diseases (3).

Bus drivers are known to be at higher risk for development of hypertension. Driving involves many risk factors such as prolonged sitting, reduced rest breaks, competing time demands, traffic congestion, and rotating duty patterns etc. The health impact of hypertension not only affects drivers themselves but also large population that depends on them for safety and interacting daily with the system (4). Hence Screening for Hypertension and Risk factors causing it, will help to identify in risk persons, to control the risk factors causing it and institute necessary Intervention. Many works have been done worldwide in studies relating to health hazards of transport bus drivers, however only few studies have been done in India. Hence this study aims to find out the association between work-related factors and hypertension and the impact of work-related factors on the employees' health

\section{METHOD}

\section{Study Design and Sample}

This Study was a Cross Sectional Study carried out in Bus Depot and Bus Stand, Chidambaram, in Cuddalore district of
Tamilnadu. The Study was carried out during April 2019 to March 2020. The approximate prevalence of HTN among Adults in Tamilnadu was 31.5\% (5).The estimated sample size for the study was 205. Ethical clearance was obtained from Institutional Ethics Committee at Raja Muthaiah Medical College, Chidambaram. Prior Consent of Participation was given to Higher Authorities and Circulated to Transport Bus Drivers through proper channel. The study area comes under service area of the medical college.

\section{Data Collection and Measurement}

A total of 205 Drivers participated in this study. All those with a Continuous Service of Minimum 2 years and irrespective of routes they drive are included in this study. Drivers who were involved in Violent physical activity, Smoking, tobacco use within thirty minutes prior to BP measurement were excluded. Driver personal details, Lifestyle, Medical History are obtained by personal Interview with a pretested semi structured questionnaire. BP was measured manually using a mercury column sphygmomanometer and stethoscope by the auscultatory method. The subject was seated comfortably for at least 15 minutes before $\mathrm{BP}$ recording. Two readings were taken one before and one after the interview, and the two were at least 15 minutes apart. The average of two readings corrected to nearest integer was taken as the BP. Patients with $\mathrm{BP}$ in prehypertensive and hypertensive range were asked to report one week later and another set of readings was obtained for confirmation. The lower of the two values was taken as the BP of the individual. BMI was calculated with subjects' height and weight. The weight was measured (closest to $1 \mathrm{~kg}$ ) using a beam type weighing scale. Height was measured (nearest to $1 \mathrm{~cm}$ ) with the subject in an erect position against a vertical surface. Hypertensives were referred for medical care and pre hypertensives were advised lifestyle modification and BP monitoring (2)

\section{Operational Definitions}

HTN was defined as systolic BP of $\geq 140 \mathrm{mmHg}$ and/or diastolic BP of $\geq 90 \mathrm{mmHg}$ or current pharmacological treatment for HTN. Pre-HTN was defined as systolic BP $120-139 \mathrm{mmHg}$ and/or diastolic BP $80-89 \mathrm{mmHg}$. Isolated systolic HTN was defined as systolic BP $\geq 140 \mathrm{mmHg}$ in presence of a normal diastolic BP (2)

A Study participant is said to be 'aware' of HTN status, if he has 
reported a diagnosis of HTN made by a Registered Medical Practitioner. 'Treatment for HTN' was defined as regular use of a prescription by a doctor for HTN. 'Control of HTN with treatment' is defined as the systolic $\mathrm{BP}<140$ and diastolic $\mathrm{BP}<$ 90 for an participant who is on regular antihypertensive drug therapy.

With respect to Personal Habits, 'Never Smoked' are participants who has never smoked cigarettes or beedis in his lifetime, 'Current Smokers' are participants who have smoked any time in past one year, 'Quit Smoke' are participants who have quitted or not smoked for past one year. Smoking is quantified in Pack years (No of packets of cigarettes * Duration of Smoking in yrs ) [1 pack $=20$ Cigarettes]. Participants are categorized into 'Never consumed alcohol' 'Takes alcohol Occasionally/Regularly' 'Quitted alcohol intake' based on their alcohol consumption habits.

With regard to Duration of Service in present job, participants are categorised as working for '2-4' yrs, '>4-7' yrs, >7-10 yrs, $>10$ yrs for finding association between HTN and Service duration. Type of Bus route the participant is driving was also an important factor and is categorised as 'Within district'- Bus routes travelling from town to town within district/town buses, 'Inter district'- Bus routes travelling from town/city from one district to other district, 'Long range route'- Bus routes travelling $>350 \mathrm{~km} / \mathrm{d}$ or routes connecting metro cities, 'Combined' - Bus routes travelling from any of above during service in an shift basis. Duration of work/driving is another important factor taken and it is represented as ' $<8 \mathrm{hrs} / \mathrm{d}$ ' , '8hrs/d', '>8hrs/d' for finding association with HTN.

\section{STATISTICAL ANALYSIS}

Data was analysed using Statistical Package for Social Sciences (SPSS) version 21.3 and Microsoft Excel. Descriptive Statistics used was mean, standard deviation, percentage. Chi-square test was used for inferential statistics

\section{RESULTS}

A total of 205 Participants were included in analysis. All study participants were male and driver by occupation. Sociodemographic characteristics of study subjects are given in Table 1.

Table 1. Distribution of Sociodemographic profile of study participants

\begin{tabular}{|l|l|}
\hline Characteristics & N (\%) \\
\hline Age (years) & \\
\hline 30 to 40 & $53(25.9 \%)$ \\
\hline 41 to 50 & $110(53.7 \%)$ \\
\hline 51 to 60 & $42(20.5 \%)$ \\
\hline Education & \\
\hline Primary & $2(1 \%)$ \\
\hline Secondary & $165(80.5)$ \\
\hline Graduate & $38(18.5)$ \\
\hline Place of Residence & \\
\hline Rural & $159(77.6 \%)$ \\
\hline Urban & $46(22.4)$ \\
\hline Marital Status & \\
\hline Unmarried & $9(4.4 \%)$ \\
\hline Married & $196(95.6 \%)$ \\
\hline Family History of Illness & \\
\hline Nil & $152(74.1 \%)$ \\
\hline Hypertension & $20(9.8 \%)$ \\
\hline Diabetes mellitus & $25(12.2 \%)$ \\
\hline Combined & $8(3.9)$ \\
\hline $\begin{array}{l}\text { Consumption of Main Meals from } \\
\text { Restaurant }\end{array}$ & \\
\hline Regularly & $16(7.8 \%)$ \\
\hline Occasionally & $189(92.2 \%)$ \\
\hline Snacks consumed between working hours & \\
\hline Up to 2 & $189(92.2 \%)$ \\
\hline & \\
\hline &
\end{tabular}

\begin{tabular}{|l|l|}
\hline More than 2 & $16(7.8 \%)$ \\
\hline Smoking & \\
\hline Non smoker & $162(79 \%)$ \\
\hline Current smoker & $42(20.5 \%)$ \\
\hline Quit Smoking & $1(0.5 \%)$ \\
\hline Alcohol & \\
\hline Non alcoholic & $132(64.4 \%)$ \\
\hline Current alcoholic & $70(34.1 \%)$ \\
\hline Quit alcohol & $3(1.5 \%)$ \\
\hline
\end{tabular}

Mean age of study participants was $45.09+/-6.1$ years (range 30-58). Mean number of years for which the study participants were in job of bus driving or Duration of service was 10.1+/4.1 (range 3-22) and during the job, the mean work hrs/day was $9.23+/-1.9$ (range $5-12$ ).

The mean Systolic BP was $133.88+/-14.49$ (range 110-220) while Diastolic BP mean was $83.5+/-9.6$ (range 60-120). The mean BMI of the Study participants was $26.7+/-3.0 \mathrm{~kg} / \mathrm{m} 2$ (range 18.6-37.8). The association between HTN and workrelated variables are shown in Tables 3 and 4. The Mean Age and other variables are shown in Table 2 .

Table 2. Mean values of variables

\begin{tabular}{|c|c|c|c|c|c|}
\hline & $\mathrm{N}$ & Minimum & Maximum & Mean & Std. Deviation \\
\hline AGE & 205 & 30 & 58 & 45.09 & 6.111 \\
\hline BMI & 205 & 18.67 & 37.87 & 26.78 & 3.0 \\
\hline SERVDYR & 205 & 3.0 & 22.0 & 10.166 & 4.1245 \\
\hline WRKHRS & 205 & 5 & 12 & 9.23 & 1.943 \\
\hline SYSTBP & 205 & 110 & 220 & 133.88 & 14.491 \\
\hline TOTAL & 205 & & & & \\
\hline
\end{tabular}

Table 3. Association between Socio-demographic factors and Hypertension

\begin{tabular}{|c|c|c|c|c|c|}
\hline \multirow[t]{2}{*}{$\overline{\text { AGE }}$} & \multirow[t]{2}{*}{$\mathbf{N}(\%)$} & \multicolumn{2}{|c|}{ Hypertension } & \multirow{2}{*}{$\begin{array}{l}\text { Test of } \\
\text { significa } \\
\text { nce }\end{array}$} & \multirow[t]{2}{*}{$\mathbf{P}$} \\
\hline & & Present & Absent & & \\
\hline 30 to 40 & $53(25.9)$ & 8 & 45 & & \\
\hline 41 to 50 & $110(53.7)$ & 45 & 65 & 71.2 & 0.08 \\
\hline 51 to 60 & $42(20.5)$ & 22 & 20 & & \\
\hline \multicolumn{6}{|l|}{ Residence } \\
\hline Rural & 159(77.6) & 55 & 104 & 4.36 & 0.11 \\
\hline Urban & $46(22.4)$ & 18 & 28 & & \\
\hline \multicolumn{6}{|l|}{ Education } \\
\hline Primary & $2(1)$ & - & 2 & & \\
\hline Secondary & $165(80.5)$ & 61 & 104 & 2.13 & 0.71 \\
\hline Graduate & $38(18.5)$ & 12 & 26 & & \\
\hline \multicolumn{6}{|c|}{ Marital Status } \\
\hline Unmarried & $9(4.4)$ & 2 & 7 & 1.33 & 0.513 \\
\hline married & $196(95.6)$ & 71 & 125 & & \\
\hline \multicolumn{6}{|c|}{ Family history of Illness } \\
\hline Nil & $152(74.1)$ & 55 & 97 & & \\
\hline Hypertension & $20(9.8)$ & 12 & 8 & 12.4 & 0.05 \\
\hline Diabetes & $25(12.2)$ & 3 & 22 & & \\
\hline Combined & $8(3.9)$ & 3 & 5 & & \\
\hline \multicolumn{6}{|c|}{ Consumption of Main meals from Restaurant } \\
\hline Regularly & $16(7.8)$ & 7 & 9 & 3.34 & 0.18 \\
\hline Occasionally & $189(92.2)$ & 66 & 123 & & \\
\hline \multicolumn{6}{|c|}{ Snacks Consumed between work hours } \\
\hline Up to 2 & $189(92.2)$ & 63 & 125 & 4.42 & 0.110 \\
\hline More than 2 & $16(7.8)$ & 9 & 7 & & \\
\hline
\end{tabular}

A Significant association is seen between duration of employment and HTN. As duration progresses hypertensive status of Study participants also increased. Mean duration of service was $10.1+/-4.1$ yrs.

In the Study Participants $11.7 \%$ were diabetic (Known DM $9.3 \%$ and Newly diagnosed $2.4 \%$ ) and among the diabetics $79.1 \%$ were hypertensive. The mean systolic value (143+/$15.2)$ and mean diastolic value $(90.29+/-8.4)$ of diabetics are higher than other hypertensive subjects. However no 
statistical significance is noted between HTN and Diabetes mellitus. Another important factor showing significant association is the Number of hours in job per day. Mean Duration of work in hours per day is $9.2+/-1.9$ with a range of 5- $12 \mathrm{hrs} /$ day

Significant association was found in work related variables like Travelling bus route (Within district, Inter-district, Long range- $>350 \mathrm{~km} /$ day) and Duration of work hours or Number of hours travelled per day $(p=0.00$ and $p=0.07$ ). Significant Association was also observed between Duration in service/ Number of years in service with Hypertension $(p=0.02)$ with a trend showing that there is an increase in prevalence of hypertension with increase in duration of Service and is shown in Table 4.

Table 4. Association between work-related factors and hypertension

\begin{tabular}{|c|c|c|c|c|}
\hline \multirow[t]{2}{*}{ Variable } & \multirow[t]{2}{*}{$\mathbf{N}(\%)$} & Hypertension & \multirow[t]{2}{*}{$\begin{array}{c}\begin{array}{c}\text { Test } \\
\text { of } \\
\text { Significance }\end{array} \\
\end{array}$} & \multirow[t]{2}{*}{$\mathbf{P}$} \\
\hline & & Present Absent & & \\
\hline \multicolumn{5}{|c|}{ Service Duration } \\
\hline 2 to 4 years & $7(3.4)$ & 7 & & \\
\hline$>4$ to 7 years & $43(20.97)$ & 35 & 20.8 & 0.002 \\
\hline$>7$ to 10 years & $58(28.29)$ & 39 & & \\
\hline$>10$ years & $97(47.3)$ & 51 & & \\
\hline \multicolumn{5}{|c|}{ Driving Bus route } \\
\hline Within district & $59(28.7)$ & 21 & & \\
\hline Inter district & $77(37.6)$ & 61 & 17.76 & 0.001 \\
\hline $\begin{array}{c}\text { Long } \\
\text { range }(>350 \mathrm{~km} / \mathrm{d})\end{array}$ & $69(33.6)$ & 36 & & \\
\hline \multicolumn{5}{|c|}{ Hours driving per day } \\
\hline Less than $8 \mathrm{hrs}$ & $4(1.9)$ & 0 & & \\
\hline $8 \mathrm{hrs}$ & $142(69.3)$ & $43 \quad 99$ & 10.6 & 0.031 \\
\hline More than $8 \mathrm{hrs}$ & $59(28.7)$ & $30 \quad 29$ & & \\
\hline \multicolumn{5}{|c|}{ Night Shifts } \\
\hline Yes & $88(42.9)$ & 42 & 10.68 & 0.005 \\
\hline No & $117(57.0)$ & $31 \quad 86$ & & \\
\hline
\end{tabular}

\section{DISCUSSION}

The present study was conducted on 205 bus drivers to find out work-related risk factors for hypertension. In this study the participants were in the age group of 30 to 60 , the mean duration of service was $10.1+/-4.1$ years with $47.5 \%$ of study participants working for $>10$ years duration \& Mean duration of Driving was $9.2+/-1.9$ hours/day which was similar to data observed by Amod L Borle et al and E.A Tobin et al (2011).

In our study, $20.5 \%$ study participants were smokers and $34.1 \%$ participants were in habit of alcohol consumption, these findings were similar to studies carried out by Beatrice olack et al(2015). A significant association is found between smoking, alcohol consumption and hypertension, however no significant association is found between smokeless tobacco use (pan) and hypertension. AmrinT Yadav(2016)et al and Masura akter khanam (2015) et al found association between smoking and hypertension, Fuh princewell(2017) et al and Kouichi sakata et al found association between alcohol consumption and hypertension. In the present study, as the Duration of work years and Duration of work per day increases there is a significant association with hypertension. Overall association of Duration of work years, Duration of work per day in hours, Driving bus route, Shift night duties are more significantly associated with Hypertension, this can be due to stress involved in work due to Prolonged sitting, Vehicle induced noise, Insomnia due to shifts, Attitudes from peoples, Smoking, alcohol etc..

\section{CONCLUSION}

Hypertension was significantly associated with various workrelated factors like Duration of service in years, Duration of hours in work per day, Driving bus route, Night shift duties and significant association also noted with personal habits like Smoking, Alcohol consumption and hypertension. Hence this study recommends regular periodic screening and regular change in work patterns with incentives like paid leaves and change in work routes in periodic basis and do regular follow up for Early diagnosis and maintain compliance with treatment for the benefit of bus drivers

\section{Limitations}

This study was carried out in Bus stands and Depots in and around Chidambaram area, in Cuddalore district of Tamilnadu. Since Chidambaram is an taluk of cuddalore district in Tamilnadu, this study findings cannot be generalised to all those having driving as profession in Tamilnadu.

\section{Financial Support \\ NIL}

\section{Conflict of interest}

There is no conflict of interest for the present study

\section{REFERENCES}

1 World Health Organization and W. van LaBerge, Primary Health Care: Now more than Ever, World Health Organization, Geneva, Switzerland, 2008

2 Arjun Lakshman, Neeraj manikath - Prevalence and Risk Factors of Hypertension among Male Occupational Bus Drivers in North Kerala, South India: $A$ Cross-Sectional Study

3. Syed Mahmood, Ausaf ahmad - Prevalence and predictors of hypertension among adults of urban Lucknow, India: A community-based study

4. Amod L borle, Ashok jadhao. Prevalence and associated factors of hypertension among occupational bus drivers in nagpur city, central india- a cross sectional study

5. Anu maria Jacob, A murugananthan. Prevalence of Hypertension among Urban Poor with and without Diabetes - A Study from South India

6. Hu B, Liu X, Yin S, et al. Effects of psychological stress on hypertension in middle-aged Chinese: a cross-sectional study. PLOS ONE 2015;10(6): e0129163

7. Guwatudde D, Mutungi G, Wesonga R, et al. The epidemiology of hypertension in Uganda: findings from the national non-communicable diseases risk factor survey. PLOS ONE 2015; 10(9): e013899

8. $\mathrm{Hu} \mathrm{W}, \mathrm{Jin} \mathrm{X}, \mathrm{Gu}$ J, et al. Risk factor panels associated with hypertension in obstructive sleep apnea patients with different body mass indexes.J Am Soc Hypertens. 2015;9(5):382-389 